\title{
Use of ground surface deformations monitoring data for control of housing facilities health
}

\author{
Svetlana Sheina ${ }^{1}$, Lidia Girya, ${ }^{1, *}$ Anastasia Lapina ${ }^{1}$ \\ ${ }^{1}$ Don State Technical University, Gagarin square 1, Rostov-on-Don, 344000, Russia
}

\begin{abstract}
The article focuses on the use of innovative technologies for Earth remote sensing (ERS) in monitoring technical conditions of buildings and structures. The proposed information support structure is based on the interferometric survey data. The example of the use of interferometric survey data in managing the technical condition of the building is considered.
\end{abstract}

\section{Introduction}

Currently, hazardous geological processes, such as groundwater surges, landslides, karst processes, and other [1-5], are observed at the territories of major cities. Objective and accurate information about dangerous man-made processes is needed to enhance reliability, durability, and safety of buildings' usage. With the development of modern innovation aerospace systems and technologies, it became possible to use Earth remote sensing (ERS) data while monitoring geological environment of territories of cities.

\section{Use of innovative Earth remote sensing technologies at managing housing stock health}

Monitoring plays an important role in housing facilities health to compare their functional status with existing standards and criteria. In order to develop the strategic management of housing facilities health of the municipality, an innovative monitoring system with the inclusion of the results of interferometric survey of Earth's surface is proposed.

Organizational and technological scheme consists of three monitoring modes: regular monitoring of housing facilities health; special housing facilities health mode for facilities with deformation of bearing structures and special monitor mode on objects that are in the zone of influence of new constructions (Figure 1). The basis for the strategy of housing facilities health management is materials with total survey conducted on special methods described in VSN 53-86 [6], according to which the physical wear of the every constructive element and for the building as a whole is determined.

* Corresponding author: giryal@inbox.ru 

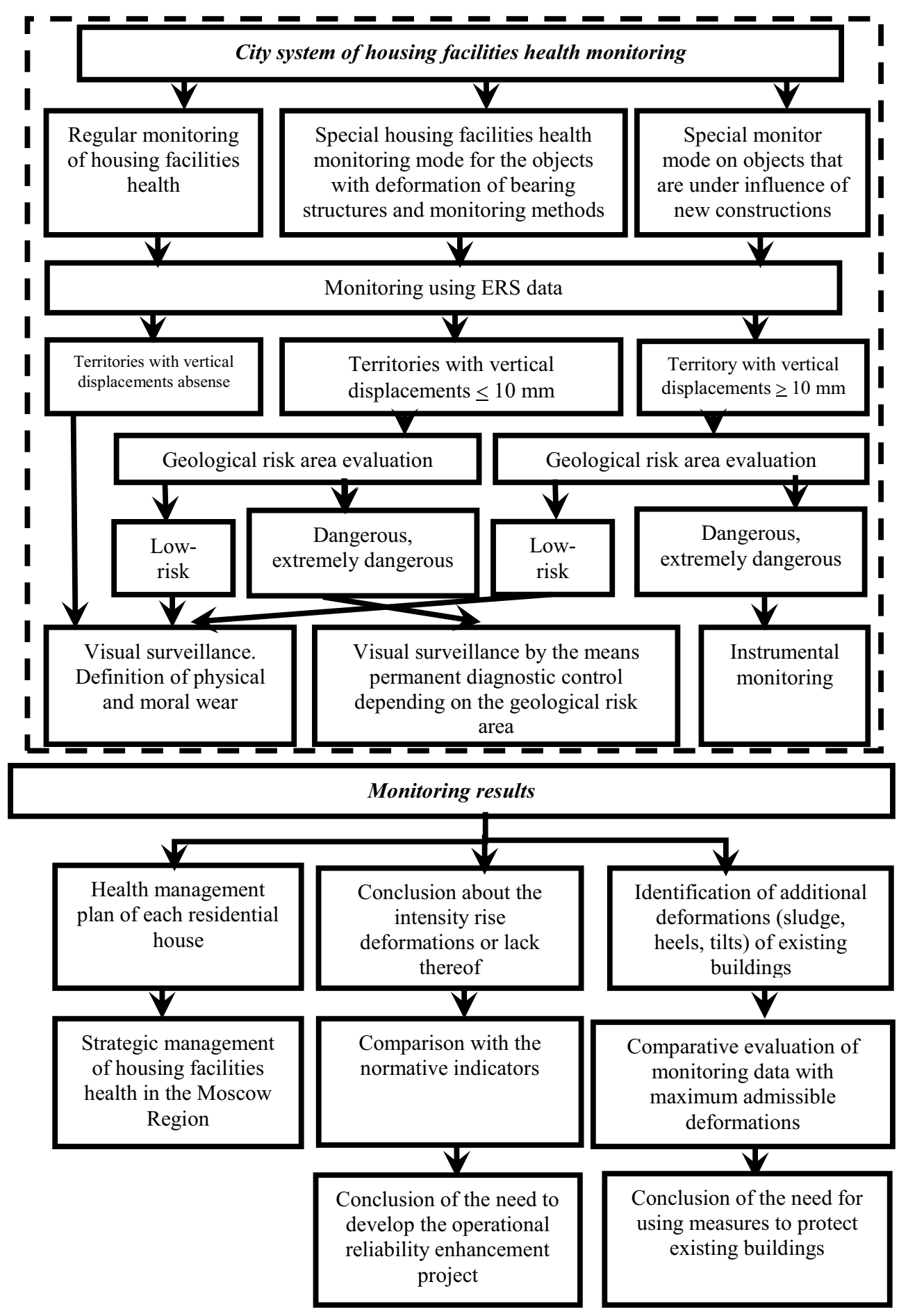

Fig. 1. Structure of housing facilities health monitoring by ERS data 


\section{The using of the information support system for housing facilities health management}

In order to monitor the territory of Rostov-on-Don, in 2011, the scientists of the sub department of Civil and Industrial Engineering School of DSTU purchased data from remote sensing radar COSMO-SkyMed satellites-1-4 (e-GEOS, Italy) for the period from May 2011 to November 2013 (40 images). Spatial resolution - $3 \mathrm{~m}$, stage size - $40 \mathrm{x} 40 \mathrm{~km}$, wave length $-3.1 \mathrm{~cm}$. Image processing was performed with the help of software by EXELIS VIS:ENVI and SARscape Interferometric Stacking [7].

ERS data is suitable for all modes, since it covers a large area, rather than a single object, but for each of the modes, depending on the condition monitoring, it provides own set of works, which includes as follows: visual surveillance; surveillance by the means of the permanent diagnostic control depending on the area of geological risk; instrumental monitoring.

Let us consider the example of a planned housing facilities health monitoring mode for residential properties, illustrating the importance and effectiveness of the proposed approach.

\section{Example 1}

Monitoring of the Earth's surface based on ERS showed that the critical value of vertical deformations of a residential building on Tokarnaya Street evolved continuously over 2011-2013. They are uneven and are concentrated in the southern wing; the difference amounted to $10-12 \mathrm{~mm}$ (Figure 2). Preliminary, it is possible to imply manifestation of deformations as a heel of the house blocks with a possible disruption of the foundation integrity. Visual survey found populating of multiple diagonal cracks in the building's concourse on contact its southern and south-western blocks. Probably, such violations in the building are not yet in sight of the service provider because they cover small amount of construction, but the monitoring data suggests that the disruption of building integrity is caused by uneven subsidence [8].

Let us consider the following example of the use of ERS in housing facilities health management. The electronic map (Figure 3) shows ArcGIS window with the data on geological risks and interferometric imagery. Interferometric survey data is shown as point objects, depending on the value of the vertical offsets. Critical values of vertical deformations are highlighted from red to blue (Figure 3).

Analysis of deformation of the Earth's surface has shown that the most unfavorable conditions are in the quarter near 58B building on Lenina avenue. Four points are selected, they are the closest to the building. They were used as a basis for the ground deformations graph, in which the dynamics of vertical deformation for 2011-2013 is present; the maximum value of which is $8-17 \mathrm{~mm}$, which indicates uneven sludge of grounds along the axis A of a building with a significant fluctuation of points (Figure 4). The most significant deformations were observed since May 2012 till February 2013, which predominate in the north wing of the building.

The concerned part is in the danger zone of the geological risk, it gives evidence of the higher possibility of dangerous geological processes occurrence [9]. 


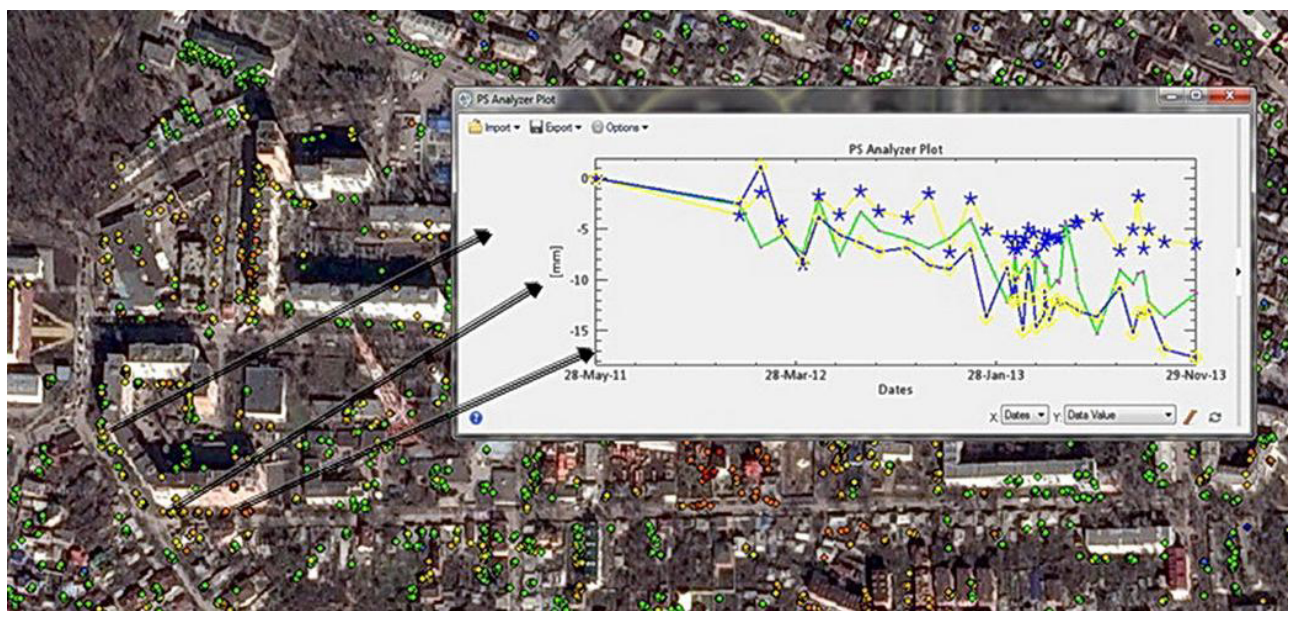

Fig. 2. Subsidence of the house on Tokarnaya street (according to Kantemirov Yu. I., 2014.)

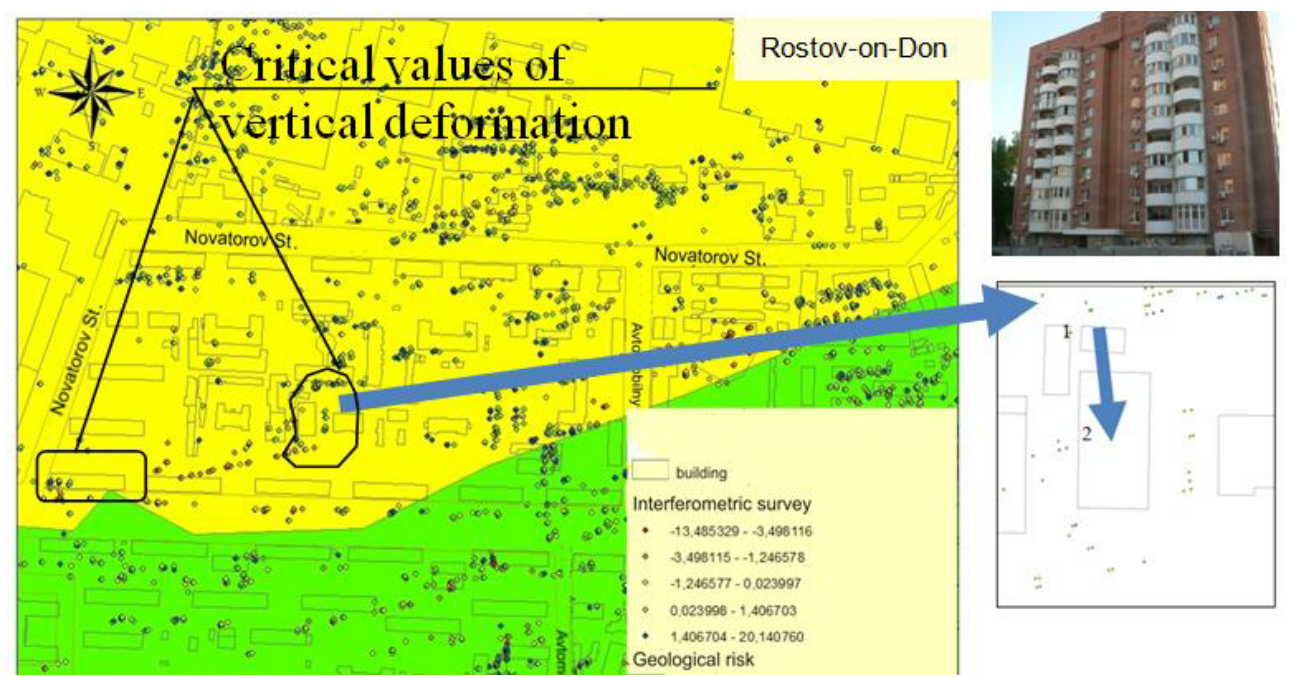

Fig. 3. Fragment of the geological risk quarter and the territory interferometric surveying data

Visual examination of residential building in 2015-2016 by test engineers from the laboratory RDE TU and CE DSTU, economic contractual works (customer was house cooperative) in monitoring of deformations of residential house located in Rostov-on-Don, at 58B Lenina avenue, has confirmed the received results.

While making observations of displacements, deformations (cracks, offsets) of walls and ceilings of the building and their evolution, plate type beacons (Figures 5-8) made of cement plaster were used.

Monitoring of the deformations of the building is conducted and it helped to reveal the fact of their accretion and alternating character of these movements (deformations) that indirectly confirms their presence in the vicinity of the residential building, recorded by the ERS method (including their character), and reflected in the graph. 


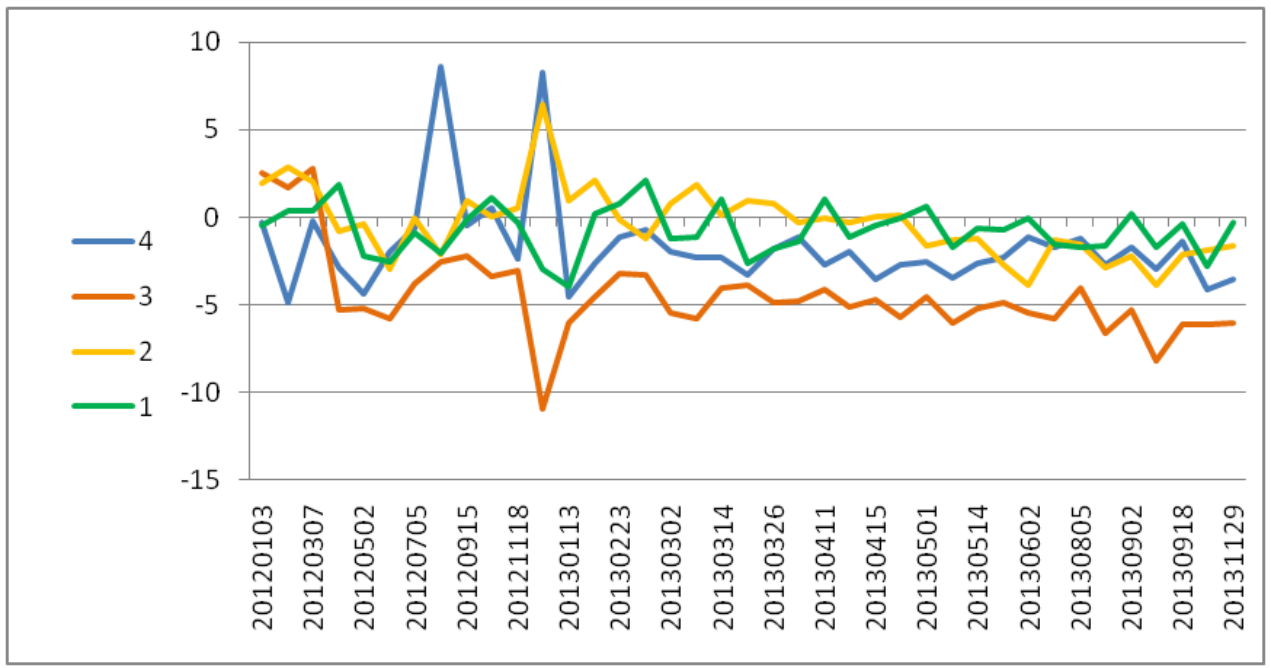

Fig. 4. Schedule of the yield of the residential building foundation on 58B Lenina avenue

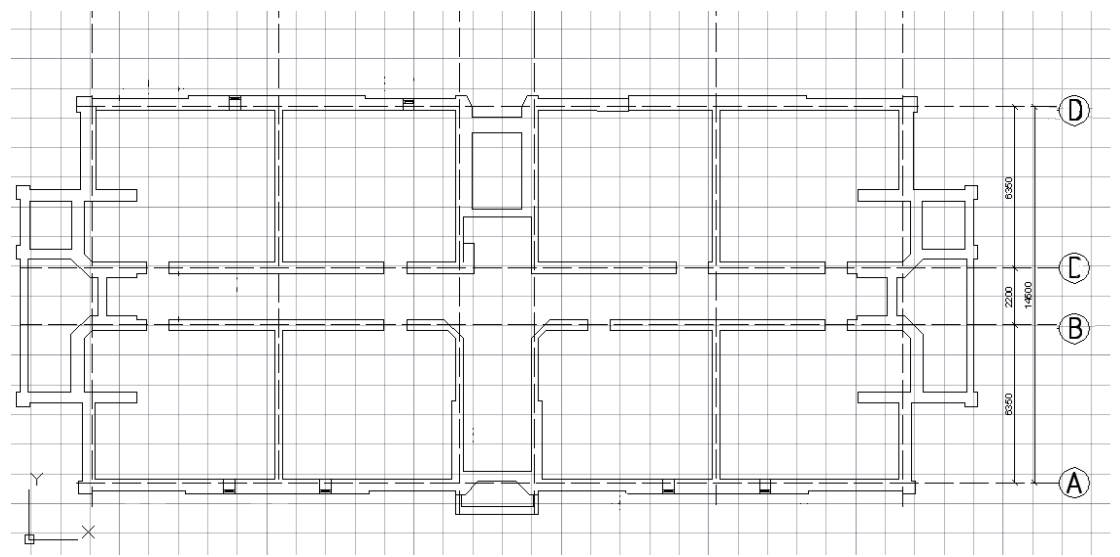

Fig. 5. Typical floor plan for a residential building

The results of monitoring based on ERS data have identified the critical values of the vertical deformations of objects, which can adversely affect the housing facilities health. Visual building survey confirmed the presence of deformations in the form of cracks and displacement of building's floors.

The above mentioned two examples illustrate the possibility of using the interferometric survey data for assessment of housing facilities health. On the possibility of preventing adverse effects on buildings in case of timely identification of dangerous geological processes, what promote to increase reliable serviceability of a building. 


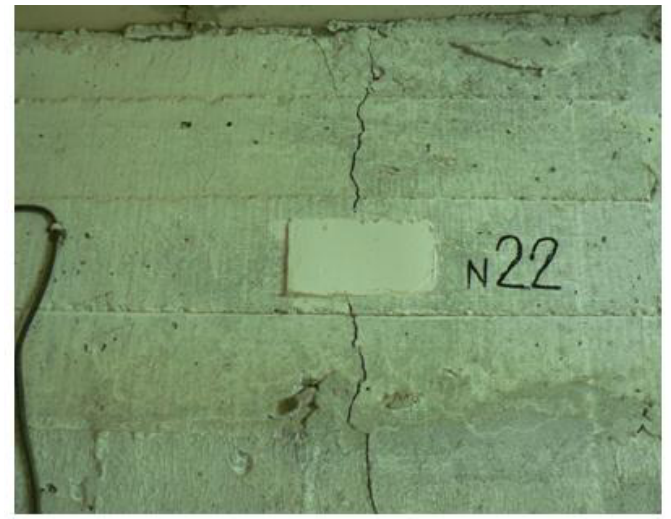

Fig. 6. Screed (No. 22), mounted on a wall of the basement near monolithic ferro-concrete belt

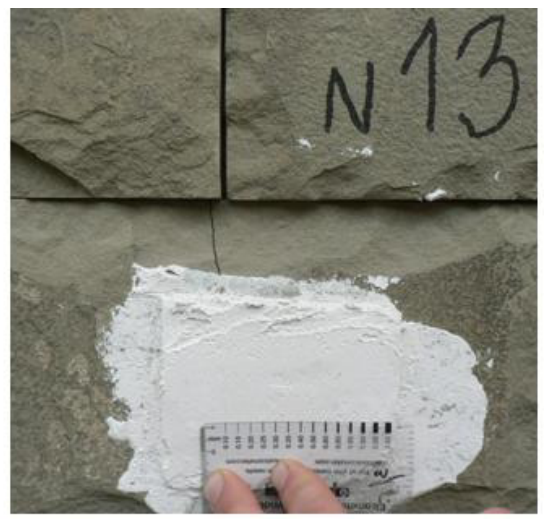

Fig. 7. Measurement of the opening of the screed (No. 13) on the outer wall of the building

\section{Conclusions}

Timely identification and analysis of ERS (interferometric mapping) on deformations of buildings and constructions allows to select the desired mode for technical health monitoring, and to increase the operational reliability of the building.

\section{References}

1. A.V. Gridnevskiy, Inzhenernyy Vestnik Dona, 3, (2013)

2. A.V. Gridnevskiy, R.B. Matveiko, Scientific review, 11-3, 678-681 (2014)

3. A.V. Gridnevskiy, AA. Hamavova, Scientific review, 11, 83-386 (2014)

4. S.G. Sheina, L.V. Girya, Inzhenernyy Vestnik Dona, 3, (2012)

5. L.V Girya, V.V Belash., S. V. Horenkov, K. S. Petrov, Inzhenernyy Vestnik Dona, 4, (2013)

6. Russian Standard VSN 53-86

7. Software by EXELIS VIS:ENVI and SARscape Interferometric Stacking.

8. P.O. Skobelev, E.V. Simonova, A.A. Zhilyaev, V.S. Travin. Procedia Computer Science, 103, 396-402 (2017)

9. S.M. Gandhi, B.C. Sarkar. Chapter 4, Remote Sensing Techniques, Essentials of Mineral Exploration and Evaluation, 81-95 (2016) 